\title{
Pembuatan Motion Graphic Sebagai Media Promosi Profil EO Batam Pos
}

\author{
Monika Pradila $^{1}$, Sandi Prasetyaningsih ${ }^{2}$ \\ Informatics Engineering, Batam State Polytechnic \\ Multimedia and Network Engineering, Batam State Polytechnic
}

\begin{tabular}{l} 
Article Info \\
\hline Article history: \\
Received Jun $12^{\text {th }}, 2021$ \\
Revised Jun $20^{\text {th }}, 2021$ \\
Accepted Jul $26^{\text {th }}, 2021$ \\
\hline
\end{tabular}

Keyword:

Event organizer

Motion graphic

Media promosi

\begin{abstract}
Event Organizer (EO) Batam Pos adalah penyedia jasa profesional penyelenggara acara dan merupakan bagian dalam PT. Sijori Interbintana Pers. EO Batam Pos belum diketahui secara luas mengingat citra merek yang sudah sangat melekat di masyarakat terhadap Batam Pos terbatas sebagai perusahaan media cetak penerbit surat kabar. Demi memaksimalkan pengetahuan masyarakat dalam mendapatkan informasi mengenai EO Batam Pos, maka dibutuhkan media untuk berpromosi. Pembuatan motion graphics dengan Research and Development (R\&D) merupakan metode yang digunakan dalam penelitian ini. Dengan hasil analisa bahwa media promosi tersebut sesuai dengan tujuan yang diharapkan, yaitu menjadi wadah dalam memberikan informasi mengenai EO Batam Pos dengan cara yang lebih efektif.

Batam Pos Event Organizer (EO) is a professional event service provider and a part of PT. Sijori Interbintana Pers. Batam Pos EO, has not famous among people since Batam Pos is well-known by newspaper publisher. A media promotion is needed in order to give much more information to public. Research and development is used as a method to do a research in producing motion graphic. The result of this study ther media promotion can give information about Batam Pos EO effectively.
\end{abstract}

\section{LATAR BELAKANG}

Event Organizer (EO) Batam Pos adalah penyedia jasa profesional penyelenggara acara dan merupakan bagian dalam event and promotion department dibawah naungan PT. Sijori Interbintana Pers [1]. Pada awalnya departemen ini dikhususkan untuk menangani berbagai kegiatan yang diselenggarakan oleh Batam Pos untuk meningkatkan Brand Awareness, kemudian berkembang menjadi sebuah organisasi penyedia jasa. EO Batam Pos belum diketahui secara luas mengingat citra merek yang sudah melekat di masyarakat terhadap Batam Pos terbatas sebagai perusahaan media cetak penerbit surat kabar. Padahal, terdapat berbagai produk dan layanan lain yang dimiliki oleh perusahaan ini, contohnya adalah Event Organizer (EO).

Promosi adalah komunikasi pemasaran selain periklanan dan hubungan masyarakat untuk memotivasi konsumen agar membeli barang atau jasa promotor [2]. PT. Sijori Interbintana Pers/Batam Pos memiliki beberapa kompetitor yang menawarkan produk atau jasa sejenis dengan yang ditawarkan kepada konsumen. teknologi mendorong pemilihan media untuk mempromosikan sebuah produk ataupun jasa tidak hanya sekedar gambar diam terpajang super besar di papan reklame atau tertera di halaman depan sebuah website atau koran. Kita mengenal adanya media berbentuk animasi yang dikenal dengan istilah motion graphic. Suatu bagian media yang memiliki basis waktu serta menggabungkan komponen dalam media visual seperti tipografi, musik dan ilustrasi disebut motion graphic [3].

Batam Pos bertransformasi menjadi media multiplatform dengan model pelayanan yang mengolaborasikan semua jenis media baik cetak ataupun online melalui program "One Stop Service". Berdasarkan latar belakang diatas, untuk memaksimalkan pengetahuan masyarakat dalam mendapatkan informasi mengenai EO Batam Pos dan mencapai tujuan program dalam perusahaan tersebut, maka dibuatlah motion graphics sebagai media untuk berpromosi yang diharapkan dapat memberi informasi mengenai jasa penyelenggara dalam bentuk yang lebih efektif dan inovatif. 


\section{LANDASAN TEORI \\ 2.1 Tinjauan Pustaka}

Tabel 1. Tinjauan Pustaka

\begin{tabular}{|c|c|c|c|c|}
\hline No. & Judul & Metode & $\begin{array}{l}\text { Peaulis } \\
\text { (Tahun) }\end{array}$ & Hasil \\
\hline 1 & $\begin{array}{l}\text { Pembuatan Motion Graphic } \\
\text { Sebagai Media Promosi Untuk } \\
\text { Proyek Jual Datsun Sigap }\end{array}$ & Kualitatif & $\begin{array}{l}\text { Agesta Budy } \\
\text { Saputra (2018) }\end{array}$ & $\begin{array}{l}\text { Media promosi Datsun } \\
\text { Sigap yang dikemas dalam } \\
\text { bentuk motion graphic }\end{array}$ \\
\hline 2 & $\begin{array}{l}\text { Pembuatan Motion Graphic } \\
\text { Sebagai Media Pembelajaran } \\
\text { Untuk Pengenalan Tata Surya } \\
\text { Pada PT. Penerbit Erlangga }\end{array}$ & Deskriptif & $\begin{array}{c}\text { Ratma Juwita } \\
\text { (2018) }\end{array}$ & $\begin{array}{c}\text { Media pembelajaran } \\
\text { pengenalan tata surya } \\
\text { berbentuk motion graphic }\end{array}$ \\
\hline 3 & $\begin{array}{c}\text { Pembuatan Video Promosi } \\
\text { Dengan Motion Graphic Pada } \\
\text { Gerakan Dan Aksi Untuk } \\
\text { Pendidikan Indonesia }\end{array}$ & $\begin{array}{c}\text { Kausal } \\
\text { Komparatif }\end{array}$ & $\begin{array}{l}\text { Fandy Adam } \\
\text { Satrio (2017) }\end{array}$ & $\begin{array}{l}\text { Video protnosi yang } \\
\text { mengimplementasikan } \\
\text { motion graphic }\end{array}$ \\
\hline
\end{tabular}

\subsection{Batam Pos}

Batam Pos merupakan salah satu penerbit surat kabar di Batam, Kepulauan Riau. PT. Sijori Interbintana Pers yang tergabung dalam Jawa Pos Group merupakan manajemen yang menaungi harian pagi Kepri tersebut. Koran ini pertama kali terbit pada 10 Agustus 1998 menggunakan nama Sijori Pos, pada tahun 2003 surat kabar berganti menjadi Batam Pos [1].

\subsection{Motion Graphic}

Salah satu bagian ilmu pengetahuan yang dikembangkan dalam teknik desain grafis adalah motion graphic, dimana komponen didalamnya dengan secara sengaja digerakkan atau diberi pergerakan seperti raut, arah, ukuran, bentuk dan tekstur [7]. Media aplikasi pada desain grafis komponennya statis (diam), sedangkan komponen pada motion graphic memiliki gerakan.

\subsection{Media Promosi}

Media merupakan bentuk perantara yang dipergunakan seseorang untuk mengemukakan atau menyebarkan gagasan sehingga segala hal yang disampaikan tersebut dapat diterima dan sampai pada akseptor yang hendak dituju [8]. Promosi merupakan suatu cara komunikasi pemasaran yang memiliki tujuan untuk menyebarkan informasi, membujuk serta mempengaruhi target pasar, diharapkan konsumen dapat bersedia menerima dan membeli produk yang sedang ditawarkan [9].

\subsection{Video Profil}

Dalam Kamus Besar Bahasa Indonesia video merupakan tayangan gambar bergerak yang disertai dengan suara yang memberikan fakta tentang hal-hal khusus dimana dalam penelitian ini merupakan informasi mengenai EO Batam Pos [10].

\subsection{EPIC Model}

Pengukuruan efektivitas media promosi dapat dilihat pengaruh komunikasinya dengan metode EPIC Model. AC Nielsen Media Research adalah perusahaan peneliti yang mengembangkannya. EPIC model terdiri dari empat dimensi, diantaranya: EPIC model terdiri atas empat dimensi, diantaranya: Empati (Empathy), Persuasi (Persuation), Dampak (Impact) dan Komunikasi (Communication) [11].

\subsection{Skala Likert}

Dalam menganalisis pendapat, sikap, dan persepsi individu atau suatu kelompok mengenai fenomena sosial peneliti dapat menggunakan Skala Likert [12]. Skala ini diambil dari nama Rensis Likert, seorang ahli psikologi sosial terkenal sekaligus penemu metode pengukuran ini .

\section{METODE PENELITIAN}

\subsection{Analisis}




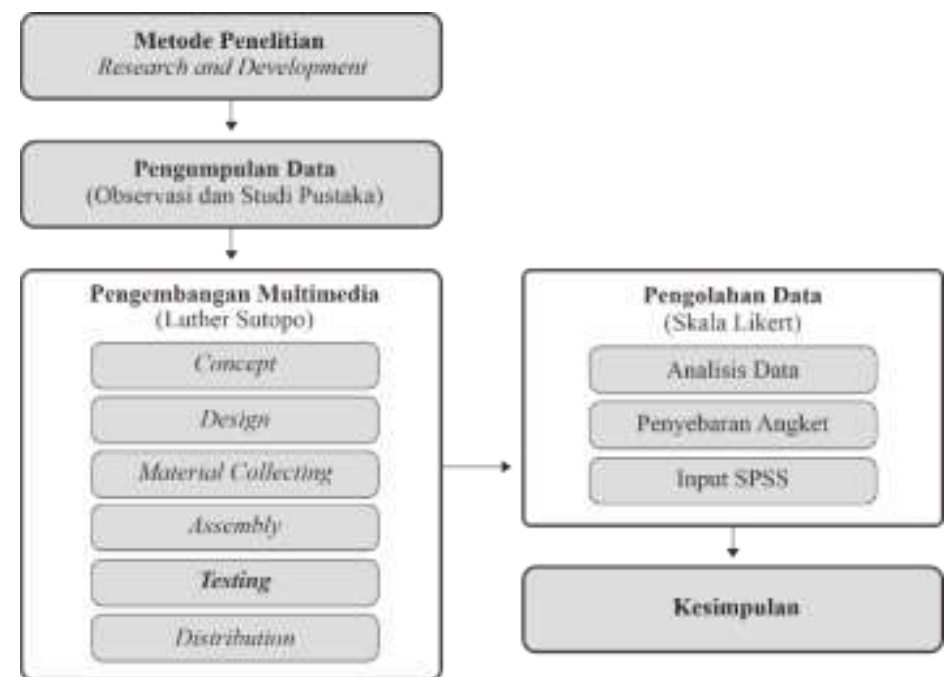

Gambar 1. Desain Penelitian

\subsection{Metode Pengumpulan Data}

\section{a. Data Primer}

Teknik pengumpulan data diperoleh melalui observasi terhadap EO Batam Pos yang kemudian menjadikannya sebuah ide dan konsep dalam penelitian pembuatan motion graphic sebagai media promosi prodil EO Batam Pos.

\section{b. Data Sekunder}

Teknik pengumpulan data dilakukan dengan studi Pustaka, yaitu mengumpulkan informasi dengan bantuan berbagai macam material yang ada di perusahaan dan pepustakaan seperti dokumen, jurnal, buku dan lain sebagainya.

\subsection{Metode Pengembangan Multimedia}

Metode pengembangan multimedia terdiri dari 6 (enam) tahapan [13], antara lain:

1. Konsep (Concept) yaitu tahapan awal dalam perancangan dimana peneliti akan menentukan tujuan dari penelitian (informasi, hiburan, promosi, dan lain sebagainya) dan identifikasi audience

2. Perancangan (Design) adalah pembuatan komponen yang dibutuhkan menggunakan metode berbasis multimedia yaitu storyboard dimana akan dilakukan pembuatan gambar sketsa pada setiap scene

3. Pengumpulan bahan (Material Collecting) yaitu mengumpulkan berbagai bahan yang dibutuhkan seperti audio, clip art dan lain sebagainya dalam proyek untuk menuju tahap pembuatan berikutnya.

4. Pembuatan (Assembly) yaitu tahap pembuatan motion graphic berdasarkan storyboard yang bersumber dari perancangan sebelumnya yang akan dijabarkan pada proses implementasi.

5. Pengujian (Testing) yaitu tahap untuk menguji coba hasil dari proyek yang telah dibuat sebelumnya. Motion graphic harus dapat berjalan baik pada media yang digunakan. Selain itu juga akan dilakukan pengolahan data untuk mengukur kefektifitasan produk.

6. Distribusi (Distribution) yaitu tahap akhir dalam pengembangan dimana proyek akan disebarluaskan melalui media digital dan menjadi salah satu aset yang dimiliki perusahaan dalam berpromosi.

\subsection{Metode Pengolahan dan Analisis Data}

Berikut merupakan metode pengolahan dan analisis data yang digunakan dalam penelitian ini:

\section{Pengolahan Data}

Skala Likert adalah teknik pengukuran yang dipergunakan dalam pengolahan data dalam penelitian ini. Responden nantinya diminta untuk melengkapi kuesioner guna memperlihatkan tingkat persetujuan mereka terhadap sekumpulan pertanyaan dalam skala sebagai berikut:
(SS) : Sangat Setuju
$=$ Diberikan nilai 5
(S) : Setuju
(RG) : Ragu-Ragu
$=$ Diberikan nilai 4
(TS) : Tidak Setuju
$=$ Diberikan nilai 3
(STS) : Sangat Tidak Setuju
$=$ Diberikan nilai 2
$=$ Diberikan nilai 1

\section{Analisis Data}

\section{a. Uji Validitas}

Uji validitas dipergunakan untuk mengetahui kelayakan sebuah instrument yang digunakan dalam pengumpulan data. Valid memiliki arti bahwa instrument dapat dipergunakan untuk mengukur 
yang seharusnya [16]. Pada penelitian ini jenis instrument yang digunakan adalah sebuah kuisioner. Taraf signifikansi pada pengujian ini ditentukan sebesar 0,05 atau sama dengan 5\%. Apabila nilai korelasi r-hitung lebih besar dari r-table, maka setiap butir kuesioner yang dimaksud adalah valid [14].

b. Uji Reliabilitas

Uji reabilitas dipergunakan untuk mengetahui apa kuisioner yang digunakan pada dasarnya menunjukkan tingkat ketepatan, keakuratan, kestabilan atau kekonsistenan dalam mengungkap indikator yang diteliti walaupun dilakukan pada waktu yang berbeda. Kuisioner dikatakan reliabel jika nilai Alpha Cronbach lebih dari 0,60 dimana merupakan standar nilai reliabilitas [15].

\subsection{Populasi dan Sampel}

Pada penelitian ini populasi adalah masyarakat Kota Batam yang merupakan sebuah wilayah generalisasi dalam penelitian, dengan jumlah sampel yang diambil adalah sebanyak 30 responden dari bagian populasi. Hal ini berdasarkan teori Roscoe yang mengatakan bahwa ukuran sampel yang cocok dalam penelitian adalah antara 30 hingga 500 [16].

\subsection{Rancangan Kuisioner}

Tabel 2. Rancangan Kuisioner

\begin{tabular}{|c|c|c|c|c|c|c|}
\hline No & Aspek & SS & $\mathrm{S}$ & RG & TS & STS \\
\hline \multirow{3}{*}{1} & Spatial & & & & & \\
\hline & Ukuran objek sudah tepat & & & & & \\
\hline & $\begin{array}{l}\text { Pergerakan antar objek tidak } \\
\text { mengganggu satu sama lain }\end{array}$ & & & & & \\
\hline \multirow{3}{*}{2} & Temporal & & & & & \\
\hline & Durasi animasi tidak terlalu lama & & & & & \\
\hline & Pergerakan setiap objek halus & & & & & \\
\hline \multirow{3}{*}{3} & Live Action & & & & & \\
\hline & Objek terlihat dengan jelas & & & & & \\
\hline & Warna latar sudah tepat & & & & & \\
\hline \multirow{3}{*}{4} & Typography & & & & & \\
\hline & Teks dapat dibaca dengan baik & & & & & \\
\hline & Ukuran teks sudah tepat & & & & & \\
\hline \multirow{3}{*}{5} & Empathy & & & & & \\
\hline & Menurut saya iklan tersebut bagus & & & & & \\
\hline & Saya menyukai iklan tersebut & & & & & \\
\hline \multirow{3}{*}{6} & Persuation & & & & & \\
\hline & Saya tertarik dengan EO Batam Pos & & & & & \\
\hline & $\begin{array}{l}\text { Saya ingin memakai jasa tersebut jika } \\
\text { suatu waktu membutuhkannya }\end{array}$ & & & & & \\
\hline \multirow{3}{*}{7} & Impact & & & & & \\
\hline & Saya menjadi lebih tahu EO Batam Pos & & & & & \\
\hline & $\begin{array}{l}\text { EO Batam Pos menjadi mudah } \\
\text { diingat dibandingkan lainnya }\end{array}$ & & & & & \\
\hline \multirow{2}{*}{8} & Communication & & & & & \\
\hline & Iklan tersebut memberi informasi & & & & & \\
\hline
\end{tabular}

\subsection{Konsep}

Pembuatan motion graphic bertujuan untuk mempromosikan Event Organizer atau EO Batam Pos agar dapat memberikan informasi tentang jasa penyelenggara tersebut kepada masyarakat luas. Media promosi berbentuk video yang mengimplementasikan motion graphic ini berdurasi 60 detik dan membahas seputar EO Batam Pos serta berbagai jasa yang ditawarkannya.

Sasaran atau target dalam promosi ini adalah instansi ataupun masyarakat menengah ke atas di perkotaan khususnya Batam, dimana kelompok konsumen pemakai jasa tersebut adalah seseorang/individu yang tidak memiliki banyak waktu untuk mengorganisir sebuah acara. 


\subsection{Perancangan}

Tabel 3. Storyboard

\begin{tabular}{|c|c|c|c|}
\hline \multirow{4}{*}{ 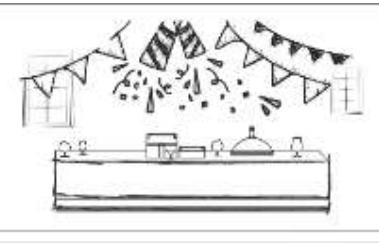 } & Seene & Duration : 5sec & \multirow{4}{*}{$\begin{array}{l}\text { Pesta dan Acara itu } \\
\text { menyenangkan, tapi, } \\
\text { merencanakannya selalu } \\
\text { merepotkan! }\end{array}$} \\
\hline & \multicolumn{2}{|c|}{$\begin{array}{l}\text { Deskripsi : } \\
\text { Pembuka video menampilkan } \\
\text { suasana saat acara berpesta }\end{array}$} & \\
\hline & Action : Pop & animation & \\
\hline & Music & yright music & \\
\hline & Scene & Duration : 5sec & \multirow{4}{*}{$\begin{array}{l}\text { Mencari layanan } \\
\text { yang dapat anda percaya } \\
\text { tidaklah mudah. } \\
\text { Tak perlu bingung! } \\
\text { Perkenalkan. }\end{array}$} \\
\hline & \multicolumn{2}{|c|}{$\begin{array}{l}\text { Deskripsi : } \\
\text { Menggambarkan seseorang yang } \\
\text { bingung saat ingin mengorganisir acara }\end{array}$} & \\
\hline & Action : Pop & : Pop up animation & \\
\hline & Music & : No copyright music & \\
\hline & Scene $: 03$ & Duration : 8 sec & \multirow{4}{*}{$\begin{array}{l}\text { EO Batam Pos: (logo) } \\
\text { Perusahaan yang bergerak } \\
\text { dalam bidang jasa } \\
\text { penyelenggara yang akan } \\
\text { membantu anda dengan } \\
\text { layanan terbaiknya. }\end{array}$} \\
\hline Estat & \multicolumn{2}{|c|}{$\begin{array}{l}\text { Deskripsi : } \\
\text { Menampilkan logo untuk } \\
\text { memperkenalkan jasa organisir }\end{array}$} & \\
\hline & Action : Pop & animation & \\
\hline & Music $\quad:$ No & yright music & \\
\hline \multirow{4}{*}{ Ourservice } & Scene $\quad: 04$ & Duration : 10sec & \multirow{4}{*}{$\begin{array}{l}\text { EO Batam pos } \\
\text { menawarkan jasa seperti : } \\
\text { 1. Corporate Event } \\
\text { 2. Seminar } \\
\text { 3. Gathering } \\
\text { 4. Exhilbition } \\
\text { 5. Charity, dan } \\
\text { 6. Competition }\end{array}$} \\
\hline & \multicolumn{2}{|c|}{$\begin{array}{l}\text { Deskripsi : } \\
\text { Menjelaskan berhagai layanan yang } \\
\text { dimiliki oleh penyedia jasa }\end{array}$} & \\
\hline & Action : Pop & animation & \\
\hline & Music : No & yright music & \\
\hline \multirow{4}{*}{ Media Branding } & Scene : 05 & Duration : 10sec & \multirow{4}{*}{$\begin{array}{l}\text { Dengan berbagai media } \\
\text { branding seperti : } \\
\text { 1. Newspaper } \\
\text { 2. Billboard } \\
\text { 3. Website } \\
\text { 4. Radio } \\
\text { 5. Television, dan } \\
\text { 6. Social Media }\end{array}$} \\
\hline & \multicolumn{2}{|c|}{$\begin{array}{l}\text { Deskripsi : } \\
\text { Menampilkan berbagai media yang } \\
\text { digunakan EO untuk berpromosi }\end{array}$} & \\
\hline & Action : Pop & animation & \\
\hline & Music $\quad$ : No & yright music & \\
\hline \multirow{4}{*}{$\begin{array}{l}\text { 1. Production } \\
\text { WHY Execution } \\
\text { US } \\
\text { 3. Amprovisation } \\
\text { 4. Analysis } \\
\text { 5. Reports dan } \\
\text { 4. Loyalty }\end{array}$} & Scene $: 06$ & Duration : 10sec & \multirow{4}{*}{$\begin{array}{l}\text { Mengapa kamu harus } \\
\text { memilih Batam Pos? karena } \\
\text { 1. Production } \\
\text { 2. Execution } \\
\text { 3. Improvisation } \\
\text { 4. Analysis } \\
\text { 5. Reports, dan } \\
\text { 6. Loyalty }\end{array}$} \\
\hline & \multicolumn{2}{|c|}{$\begin{array}{l}\text { Deskripsi : } \\
\text { Memberikan alasan mengapa harus } \\
\text { memilih EO Batam Pos }\end{array}$} & \\
\hline & Action : Pop & animation & \\
\hline & \multicolumn{2}{|c|}{ Music : No copyright music } & \\
\hline \multirow{4}{*}{$\infty=$} & Scene $\quad: 07$ & Duration : 8sec & \multirow{4}{*}{$\begin{array}{l}\text { Kami melakukan } \\
\text { semuanya untuk anda! } \\
\text { Segera Hubungi kami! }\end{array}$} \\
\hline & \multicolumn{2}{|c|}{$\begin{array}{l}\text { Deskripsi : } \\
\text { Pencantuman data penting seperti } \\
\text { alamat, email dan nomor handphone }\end{array}$} & \\
\hline & \multicolumn{2}{|c|}{ Action : Pop up animation } & \\
\hline & \multicolumn{2}{|c|}{ Music $\quad$ : No copyright music } & \\
\hline \multirow{4}{*}{ 40 Batam Pos } & Scene & Duration : $4 \mathrm{sec}$ & \multirow{4}{*}{$\begin{array}{l}\text { EO Batam Pos (Logo) } \\
\text { We Create. You Celebrate. }\end{array}$} \\
\hline & \multicolumn{2}{|c|}{$\begin{array}{l}\text { Deskripsi : } \\
\text { Menampilkan logo sebagai penutup }\end{array}$} & \\
\hline & \multicolumn{2}{|c|}{ Action : Pop up animation } & \\
\hline & \multicolumn{2}{|c|}{ Music $\quad$ : No copyright music } & \\
\hline
\end{tabular}

\section{HASIL DAN PEMBAHASAN}

Berdasarkan metode Luther Sutopo yang digunakan dalam penelitian, bagian ini merupakan lanjutan pengembangan yang menampilkan hasil implementasi pada pembuatan motion graphic sebagai media promosi profil EO Batam Pos. Tahapan tersebut terdiri dari Pengumpulan bahan (material collecting), pembuatan (assembly), pengujian (testing) dan distribusi (distribution).

\subsection{Pengumpulan Bahan}

Berikut merupakan hasil pengumpulan bahan berupa gambar dan audio yang telah tersusun dalam folder dan ditunjukkan pada gambar 2. 


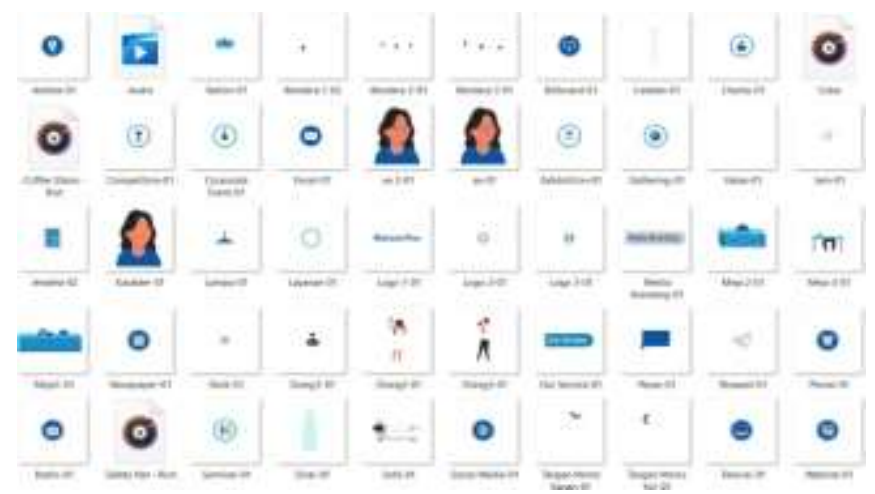

\subsection{Pembuatan}

Gambar 2. Pengumpulan Bahan

1. Tracing dan Coloring

Dalam pembuatan objek dilakukan tracing dan coloring dengan menggunakan software CorelDRAW. Tahap ini diperuntukkan untuk mengubah hasil sketsa kedalam bentuk digital dengan memanfaatkan fitur pen dan interactive fill tool seperti hasil storyboard pada tabel 4.

Tabel 4. Tracing dan Coloring

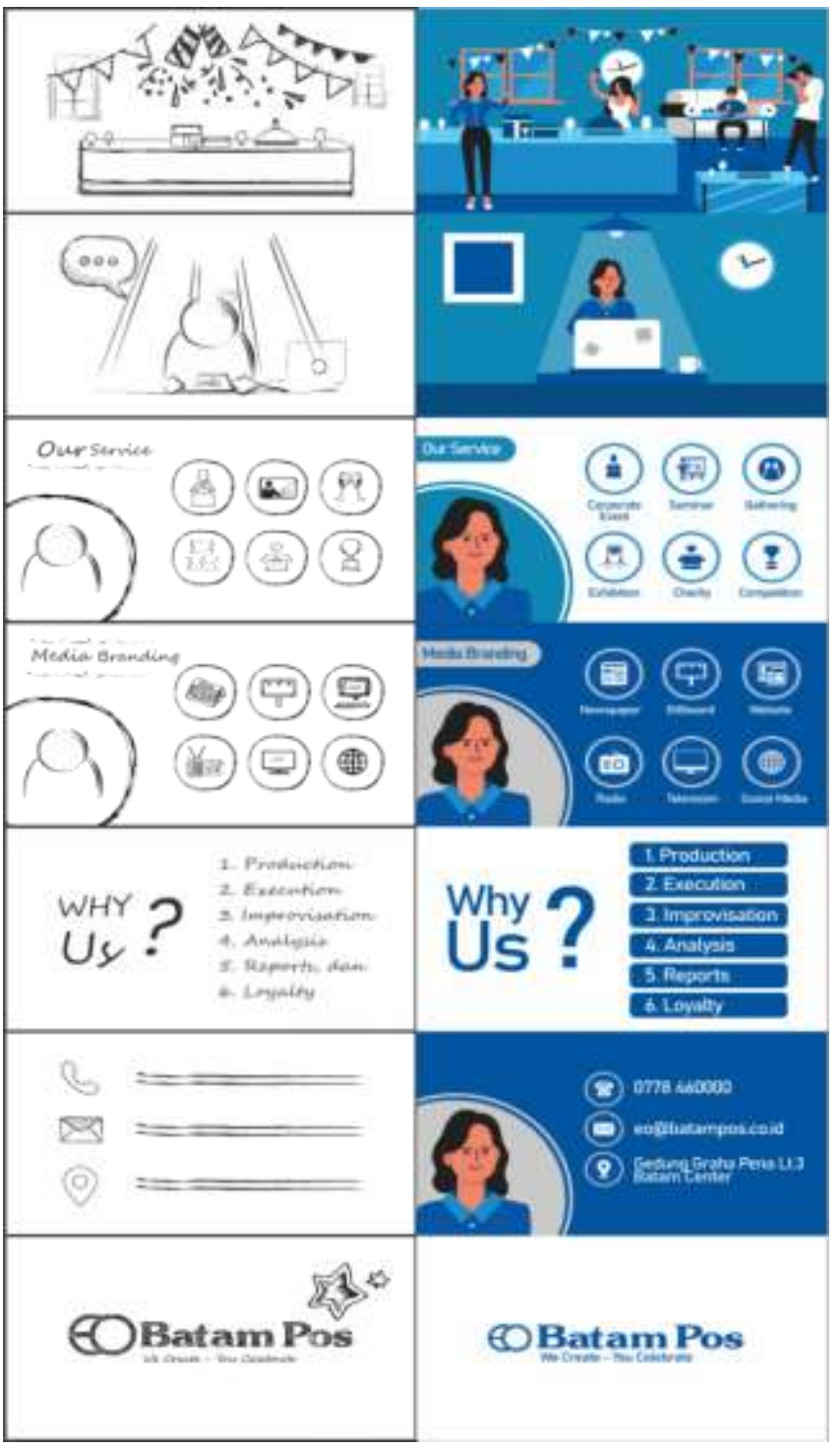

\section{Animating}

Setelah tracing dan coloring, dilanjutkan dengan proses animating menggunakan software Adobe After Effect. Tahap ini diperuntukkan untuk mengubah objek dan karakter menjadi dinamis sehingga dapat bergerak dan terkesan hidup dengan menggunakan teknik keyframe, yaitu pemberian 
kunci pada frame di awal dan akhir dengan memanfaatkan elemen seperti scale, rotation dan position seperti pada gambar 3 .

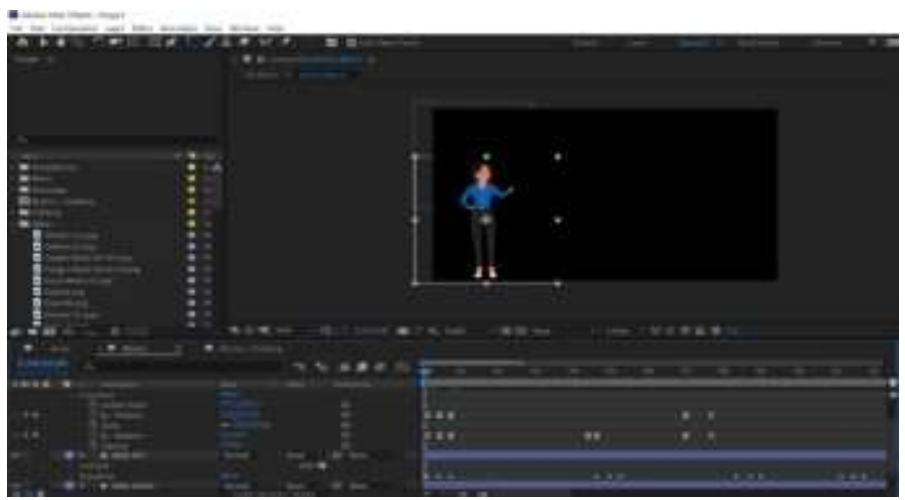

Gambar 3. Animating

\section{Dubbing}

Penyulihan suara atau dubbing adalah tahap perekaman suara yang diperuntukkan sebagai narasi pengiring dari video pembuatan motion graphic sebagai media promosi EO Batam Pos sehingga lebih mudah dipahami. Pada penelitian ini dubbing menggunakan jasa orang lain, yaitu Febria Hanum yang berprofesi sebagai news anchor salah satu stasiun televisi lokal yang bertempat di Batam dengan memanfaatkan aplikasi Voice Memos pada telepon seluler.

\section{Editing}

Setelah semua bahan baik objek, animasi, dan audio telah selesai dilanjutkan dengan proses editing menggunakan software Adobe Premiere Pro. Tahap ini merupakan proses penyuntingan meliputi pemotongan, pemberian efek, pengga-bungan animasi dan audio pada gambar 4.

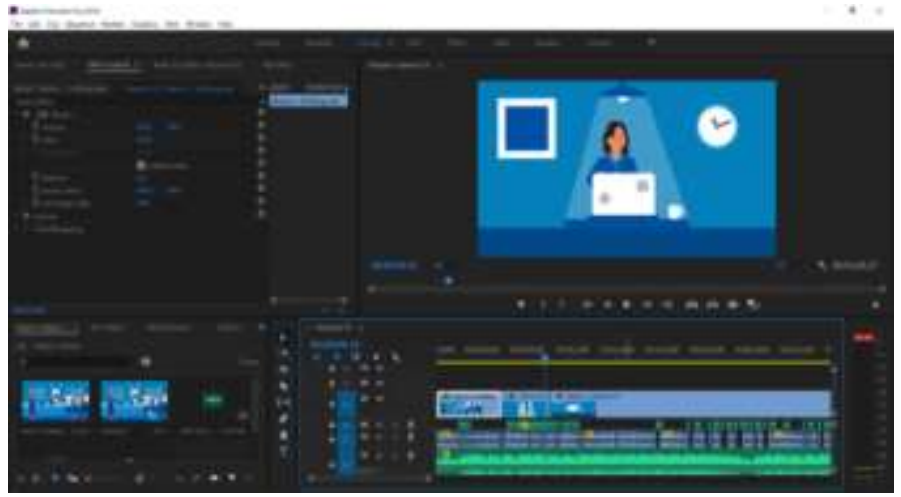

\section{Rendering}

\section{Gambar 4. Editing}

Rendering merupakan tahap penyatuan hasil penyuntingan menjadi satu kesatuan video yang utuh menggunakan software Adobe Premiere Pro dan dapat dinikmati dengan output berupa format MP4 seperti pada gambar 5.

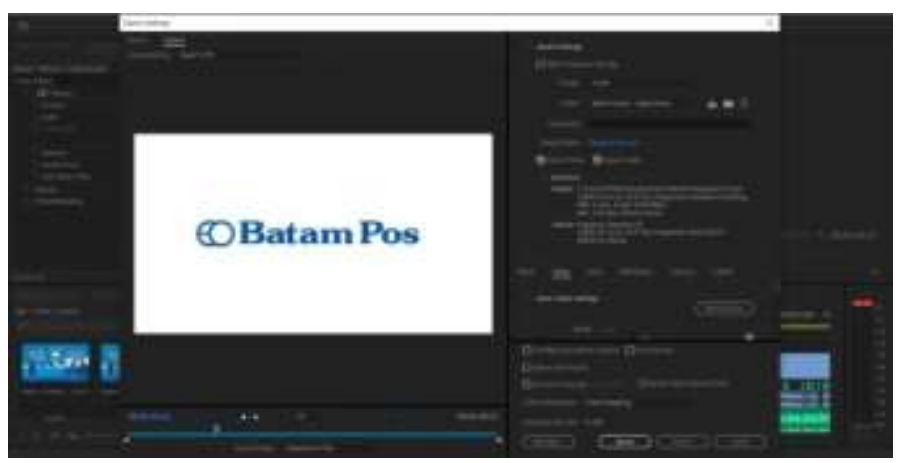

Gambar 5. Rendering

\subsection{Pengujian}

Terdapat dua buah pengujian yang dilakukan dalam penelitian ini, diantaranya sebagai berikut:

\section{a. Alpha Testing}

Pada alpha testing akan dilakukan 2 (dua) buah pengujian yang nantinya akan digunakan sebagai 
alat ukur, yaitu uji validitas dan uji reliabilitas dengan penjabaran sebagai berikut:

\section{Uji Validitas}

Perhitungan uji validitas dalam hal ini menggunakan bantuan aplikasi IBM SPSS Statistic. Setelah didapatkan nilai korelasi r-hitung, tahap selanjutnya adalah membandingkan nilai r-hitung dengan nilai r-tabel agar dapat diketahui setiap butir pertanyaan yang ada pada kuisioner valid atau bahkan sebaliknya. Berikut merupakan hasil perbandingan pada tabel 5 .

Tabel 5. Hasil Uji Validitas

\begin{tabular}{|c|c|c|c|c|}
\hline No & Pertanyaan & r-hitung & $\begin{array}{c}\text { r-tabel } \\
(\alpha=0,05)\end{array}$ & Hasil \\
\hline 1 & Ukuran objek sudah tepat & 0.736 & 0,361 & Valid \\
\hline 2 & $\begin{array}{l}\text { Pergerakan antar objek tidak } \\
\text { mengganggu satu sama lain }\end{array}$ & 0.669 & 0,361 & Valid \\
\hline 3 & Durasi animasi tidak terlalu lama & 0.447 & 0,361 & Valid \\
\hline 4 & Pergerakan setiap objek halus & 0.546 & 0,361 & Vahid \\
\hline 5 & Objek terlihat dengan jelas & 0.626 & 0,361 & Valid \\
\hline 6 & Warna latar sudah tepat & 0.593 & 0,361 & Valid \\
\hline 7 & Teks dapat dibaca dengan balk & 0.538 & 0,361 & Valid \\
\hline 8 & Ukuran teks sudah tepat & 0.689 & 0,361 & Valid \\
\hline 9 & Menurut saya iklan tersebut bagus & 0.786 & 0,361 & Valid \\
\hline 10 & Saya menyukai iklan tersebut & 0.842 & 0,361 & Valid \\
\hline 11 & Saya tertarik dengan EO Batam Pos & 0.795 & 0,361 & Valid \\
\hline 12 & $\begin{array}{l}\text { Saya ingin memakai jasa tersebut } \\
\text { jika stuatu waktu membutuhkannya }\end{array}$ & 0.736 & 0,361 & Valid \\
\hline 13 & $\begin{array}{l}\text { Saya menjadi lebih tahu } \\
\text { tentang EO Batam Pos }\end{array}$ & 0.630 & 0,361 & Vahid \\
\hline 14 & $\begin{array}{l}\text { EO Batam Pos menjadi mudah } \\
\text { diingat dibandingkan lainnya }\end{array}$ & 0.601 & 0,361 & Valid \\
\hline 15 & Iklan tersebut memberi informasi & 1 & 0,361 & Valid \\
\hline
\end{tabular}

\section{Uji Reabilitas}

Setelah didapatkan hasil uji validitas, dilanjutkan dengan menghitung nilai Alpha Cronbach menggunakan aplikasi IBM SPSS Statistic. Selanjutnya adalah menentukan apakah kuisioner yang digunakan pada penelitian ini reliabel atau bahkan sebaliknya. Berikut merupakan hasil perhitungan uji reabilitas pada tabel 6 .

Tabel 6. Hasil Uji Reliabilitas

\begin{tabular}{|c|c|c|}
\hline Alpha Cronbach & n of Items & Hasil \\
\hline 0,965 & 15 & Reliabel \\
\hline
\end{tabular}

\section{b. Beta Testing}

Setelah diketahui bahwa kuisioner yang digunakan sudah valid dan reliabel, selanjutnya dihitung tingkat efektifitas motion graphic dan media promosi menggunakan skala likert. Pengukuran tingkat efektivitas dari video promosi dilakukan dengan menganalisa jawaban yang diperoleh dari kuisioner.

\section{Spatial}

Aspek ini memberikan informasi apakah video promosi mempertimbangkan ukuran dan hubungan terhadap batas-batas frame agar elemen visual bergerak selaras. Hasil perhitungan analisis untuk aspek Spatial mendapatkan index sebesar 90,67\% pada interpretasi skor. Hal ini mengindikasi bahwa penonton "Sangat Setuju" jika video promosi yang disajikan memiliki ukuran objek yang tepat dan pergerakan objek tidak mengganggu satu sama lain.

\section{Temporal}

Aspek ini memberikan informasi apakah video promosi mempertimbangkan waktu dan kecepatan dalam menciptakan pergerakan. Hasil perhitungan analisis untuk aspek Temporal mendapatkan index sebesar 89,33\% pada interpretasi skor. Hal ini mengindikasi bahwa penonton "Sangat Setuju" jika video promosi yang disajikan memiliki durasi animasi yang tidak terlalu lama dan halus.

\section{Live Action}

Aspek ini memberikan informasi apakah video promosi mempertimbangkan property dan sifat sinematik agar motion graphic memiliki daya tarik visual yang jelas. Hasil perhitungan analisis untuk 
aspek Live Action mendapatkan index sebesar 89,33\% pada interpretasi skor. Hal ini mengindikasi bahwa penonton "Sangat Setuju" jika video promosi yang disajikan memiliki objek yang terlihat dengan jelas dengan warna latar yang sudah tepat.

\section{Typography}

Aspek ini memberikan informasi apakah video promosi mempertimbangkan tipe huruf dan ukuran untuk mewakili konsep yang terdapat dalam format visual. Hasil perhitungan analisis untuk aspek Typography mendapatkan index sebesar $89 \%$ pada interpretasi skor. Hal ini mengindikasi bahwa penonton "Sangat Setuju" jika video promosi yang disajikan memiliki teks yang dapat dibaca dengan baik dengan ukuran tulisan yang sudah tepat.

Berikut merupakan hasil perhitungan aspek motion graphic yang ditunjukkan pada tabel 7.

Tabel 7. Skor aspek motion graphic

\begin{tabular}{|c|c|c|}
\hline Aspek Motion Graphic & Total Skor & Persentase \\
\hline Spatial & 136 & $90,67 \%$ \\
\hline Temporal & 134 & $89,33 \%$ \\
\hline Live Action & 134 & $89,33 \%$ \\
\hline Typography & 133,5 & $89 \%$ \\
\hline
\end{tabular}

Berdasarkan tabel 4.13 didapatkan total skor dan persentase dari tiap aspek motion graphic. Selanjutnya adalah menghitung nilai rata-rata dengan rumus sebegai berikut:

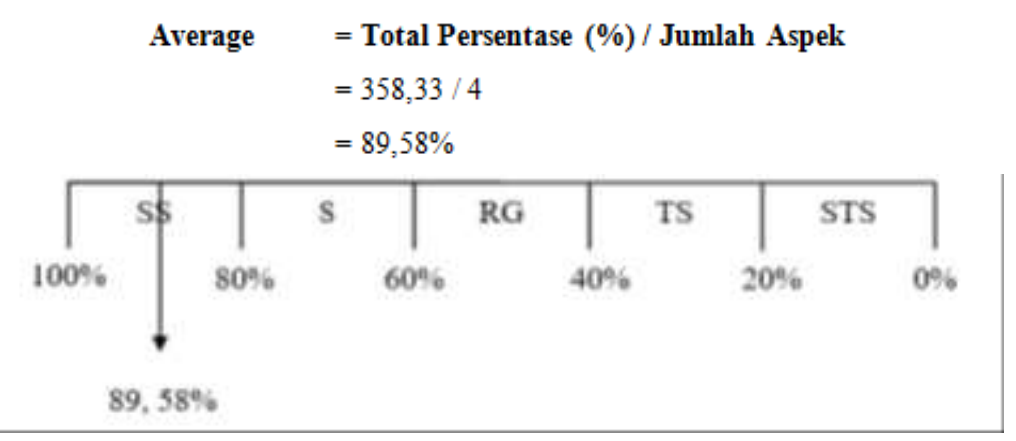

Hasil perhitungan rata - rata dalam tiap aspek mendapatkan index sebesar 89,58\% pada interpretasi skor. Hal ini mengindikasi bahwa responden beranggapan "Sangat Setuju" jika video promosi yang dibuat mengimplementasikan tiap aspek pada motion graphic, sehingga dapat menjadi salah satu media promosi EO Batam Pos dalam memberikan informasi yang lebih efektif . Dalam hal ini, maka tugas utama dari pembuatan media promosi berbentuk motion graphic terpenuhi.

\section{Empathy}

Dimensi ini memberikan informasi akankah konsumen menyukai sebuah produk atau jasa serta memberikan gambaran bagaimana konsumen melihat hubungan antara diri mereka dengan suatu iklan. Hasil perhitungan analisis untuk dimensi empathy mendapatkan nilai 4,55 pada skala EPIC Model, dimana berada di rentang penilaian Sangat Efektif. Hal ini mengindikasi bahwa konsumen menyukai video promosi yang disajikan.

\section{Persuation}

Dimensi ini menjelaskan bagaimana komunikasi promosi dapat mempengaruhi sikap, perubahan kepercayaan dan perilaku. Hasil perhitungan analisis untuk dimensi persuation mendapatkan nilai 4,51 pada skala EPIC Model, dimana berada di rentang penilaian Sangat Efektif. Hal ini mengindikasi bahwa video promosi yang dibuat dapat membuat konsumen tertarik dengan jasa/produk yang ditawarkan.

\section{Impact}

Dimensi ini mengungkapkan apakah pesan yang terdapat dalam media promosi tersampaikan dengan baik kepada konsumen sehingga suatu produk/jasa dapat terlihat menonjol dibanding lainnya.

Hasil perhitungan analisis untuk dimensi impact mendapatkan nilai 4,61 pada skala EPIC Model, dimana 4,61 berada di rentang penilaian Sangat Efektif. Hal ini mengindikasi bahwa video yang dibuat menjadikan konsumen lebih mengetahui dan mengingat EO Batam Pos. 


\section{Communication}

Dimensi ini menginformasikan bagaimana kemampuan dan tingkat pemahaman konsumen saat mengingat pesan pokok yang ingin disampaikan dan juga kesan yang tertinggal dalam iklan. Hasil perhitungan analisis untuk dimensi communication mendapatkan nilai 4,57 pada skala EPIC Model, dimana 4,57 berada di rentang penilaian Sangat Efektif. Hal ini mengindikasi bahwa video promosi yang dibuat dapat memberikan informasi.

\section{EPIC Rate}

Setelah nilai dalam tiap dimensi sudah didapatkan maka dilanjutkan dengan melakukan perhitungan EPIC Rate, yaitu perhitungan rata-rata dimensi yang ditunjukkan pada tabel 8.

Tabel 8. Skor Aspek Promosi

\begin{tabular}{|c|c|c|}
\hline Aspek Promosi & Nilai & Keterangan \\
\hline Empathy & 4.55 & Efektif \\
\hline Persuation & 4.51 & Efektif \\
\hline Impact & 4.61 & Efektif \\
\hline Communication & 4.57 & Efektif \\
\hline
\end{tabular}

EPIC Rate $=\frac{4,55+4,51+4,61+4,57}{4}=4,56$

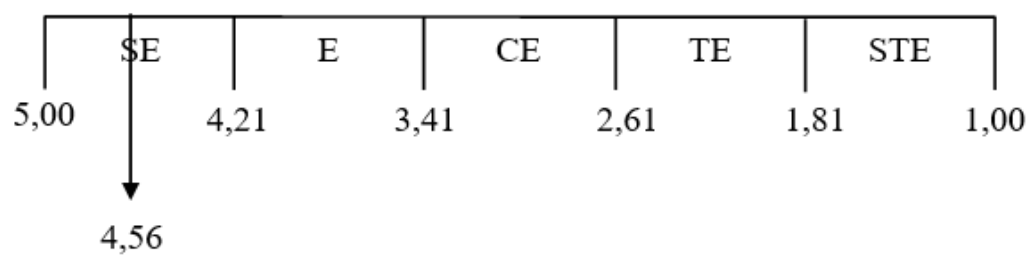

Hasil perhitungan rata - rata dalam tiap dimensi atau EPIC Rate mendapatkan nilai 4.56, dimana 4.56 berada di rentang penilaian Sangat Efektif. Hal ini mengindikasi bahwa media promosi yang dibuat disukai oleh penonton, dapat meyakinkan pengguna, menarik perhatian, mudah diingat, serta memberikan informasi dan pengetahuan mengenai EO Batam Pos. Secara keseluruhan hasil analisa menggunakan EPIC model ditunjukkan pada gambar 6.

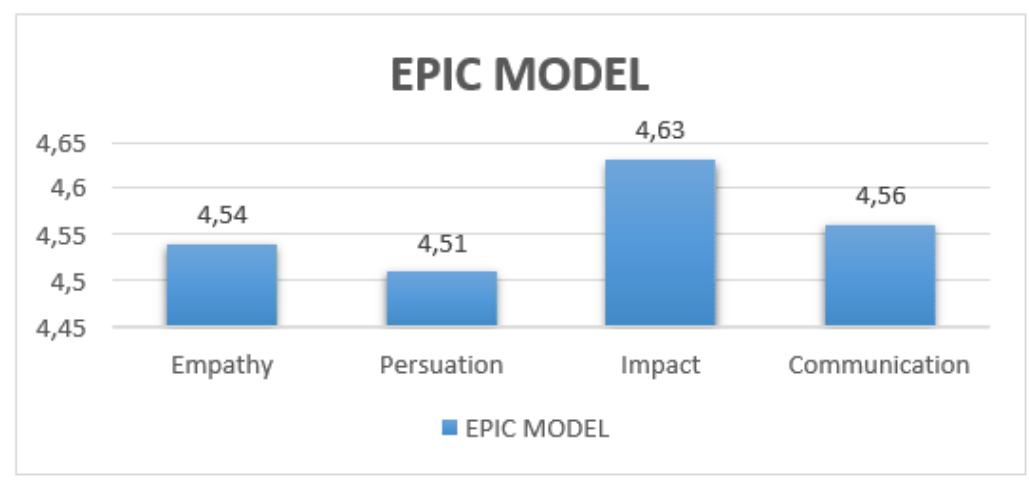

Gambar 6. Grafik EPIC Model

\subsection{Distribusi}

Pada tahapan ini dilakukan penyebarluasan video promosi yang telah dibuat melalui berbagai media seperti : website batampos.id dan youtube Batam Pos, sehingga dapat memudahkan peneliti dalam menarik target audience yang diinginkan seperti pada gambar 7 dan 8 . 


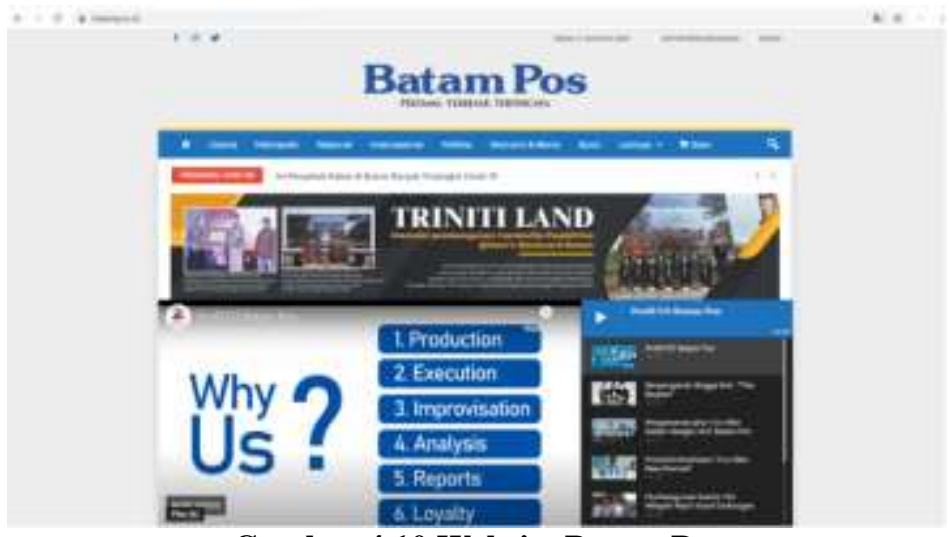

Gambar 4.10 Website Batam Pos

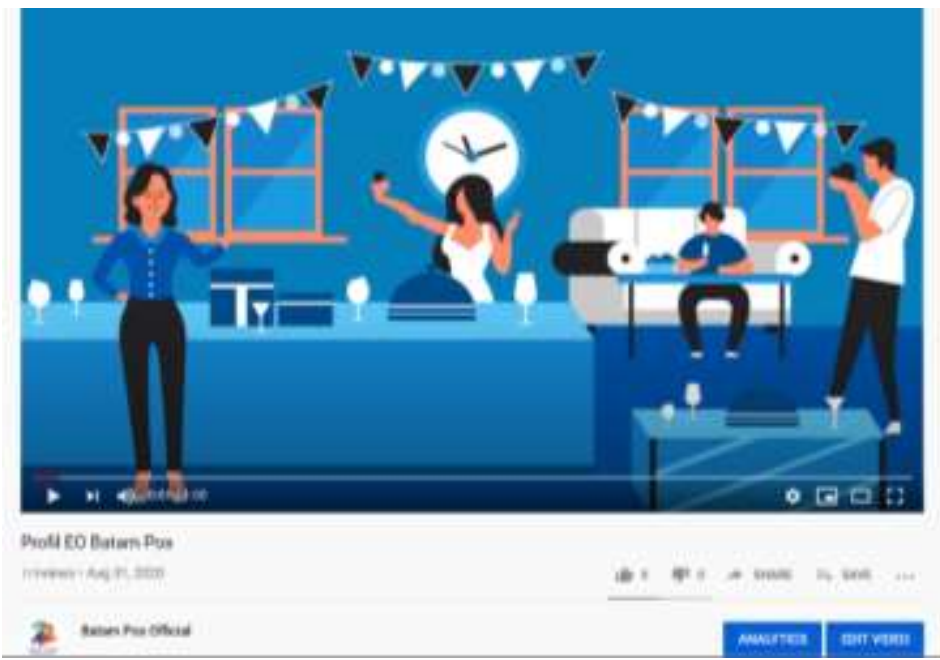

Gambar 4.11 Youtube Batam Pos

\section{KESIMPULAN}

Berdasarkan hasil penelitian yang telah dilakukan dalam penulisan tugas akhir ini, maka dapat diambil beberapa kesimpulan diantaranya :

1. Sebelumnya jasa penyelenggara ini belum diketahui secara luas, mengingat citra merek yang sudah melekat di masyarakat terhadap Batam Pos terbatas sebagai perusahaan media cetak penerbit surat kabar. Dengan adanya media promosi dalam bentuk video yang mengimplementasikan motion graphic tersebut, seluruh informasi terhadap EO Batam Pos dapat lebih mudah diakses melalui media elektronik apa saja oleh visitor dari berbagai kalangan sebagai target audience dalam market penjualan..

2. Pembuatan video yang mengimplementasikan tiap aspek pada motion graphic untuk mempromosikan EO Batam Pos, menjadi bahan promosi yang tepat karena lebih mudah dipahami dan efektif dalam menyampaikan informasi kepada masyarakat luas pada masa sekarang.

3. Diketahui dari hasil analisis menggunakan EPIC Model, peneliti mendapatkan skor 4,56. Dimana penilaian ini berada di rentang "Sangat Efektif" dalam EPIC Rate. Hal ini mengindikasikan bahwa media promosi yang dibuat berhasil disukai oleh penonton, dapat meyakinkan pengguna, menarik perhatian, mudah diingat, serta memberikan informasi dan pengetahuan mengenai EO Batam Pos.

\section{DAFTAR PUSTAKA}

[1] Batam Pos. (2018). Media Kit Batam Pos. Batam : PT. Sijori Interbintana Pers.

[2] Lamb, C. W, Joseph F. Hair, C. McDaniel. (2001). Pemasaran. Edisi pertama. Jakarta : Salemba Empat.

[3] Sukarno. (2014). Perancangan Video Media Promosi Berbasis Motion Graphic 2D Untuk Meningkatkan Jumlah Mahasiswa. Jointecs.

[4] Saputra, B. S. (2018). Pembuatan Motion Graphic Sebagai Media Promosi Untuk Proyek Purna Jual Datsun Sigap. KOPERTIP: Jurnal Ilmiah Manajemen Informatika dan Komputer, 02, 89 - 47.

[5] Juwita, Ratna. (2018). Pembuatan Motion Graphic Sebagai Media Pembelajaran Untuk Pengenalan Tata Surya Pada PT. Penerbit Erlangga. KOPERTIP: Jurnal Ilmiah Manajemen Informatika dan Komputer. 
[6] Satrio, F. A. (2017) Pembuatan Video Promosi Dengan Motion Graphic Pada Gerakan Dan Aksi Untuk Pendidikan Indonesia. Skripsi. Jurusan Sistem Informasi. Universitas AMIKOM. Yogyakarta.

[7] Umam, N. C. (2016). Perancangan Motion Graphic Pengenalan Batik Gemawang Khas Kabupaten Semarang. Jurnal Tugas Akhir.

[8] Arsyad, Azhar. (2014). Media Pembelajaran. Jakarta : PT. Rajagrafindo Persada.

[9] Tjiptono. (2001). Manajemen Pemasaran dan Analisa Perilaku Konsumen. Yogyakarta : BPFE.

[10] KBBI. (2016). Video. Diakses pada 25 Juni 2020, dari https://kbbi.web.id/video

[11] Durianto, Darmadi, Sugiarto, Anton, dkk. (2003). Invasi Pasar dengan Iklan yang Efektif. Jakarta: PT. Gramedia Pustaka Utama.

[12] Sugiyono. (2010). Metode Penelitian Pendidikan Pendekatan Kuantitatif, kualitatif, dan R\&D. Bandung

[13] Sutopo, A. H. (2003). Multimedia Interaktif dengan Flash. Yogyakarta

[14] Nugroho, B. A. ( 2005). Strategi Jitu Memilih Metode Statistik Penelitian dengan SPSS. Yogyakarta: ANDI.

[15] Wahana Komputer. (2012). Solusi Praktis \& Mudah SPSS 20 untuk Pengolahan Data. Yogyakarta : Andi Publisher.

[16] Sugiyono. (2009). Metode Penelitian Bisnis, Bandung : CV. Alfabeta. 